\title{
Aid Effectiveness and Governance
}

\section{The Good, the Bad and the Ugly}

\section{BY DANIEL KAUFMANN}

\section{The Good}

AID EFFEGTIVENESS HAS BECOME a central notion in the lexicon of the aid industry, in contrast to over two decades ago, when official donors would not hesitate to provide major funding to governments like that of Mobutu in Zaire and Marcos in the Philippines. Such extreme misgovernance in official aid by traditional donors is rare today. For instance, even though multilateral financial institutions have been silent about the governance debacle in Zimbabwe, at least they have refrained in recent times from funding Mugabe's government.

Further, for over a decade there has been increasing recognition that aid flowing to governments implementing ineffective policies is wasteful, consistent with empirical findings already available in the early 1990s. As a result, over the past decades aid has become somewhat more sensitive to support-

FIGURE 1: DEVELOPING COUNTRY STAKEHOLDER VIEWS ON WORLD BANK FUNDING-WITH HIGH LEVEL OF CORRUPTION IN THE COUNTRY

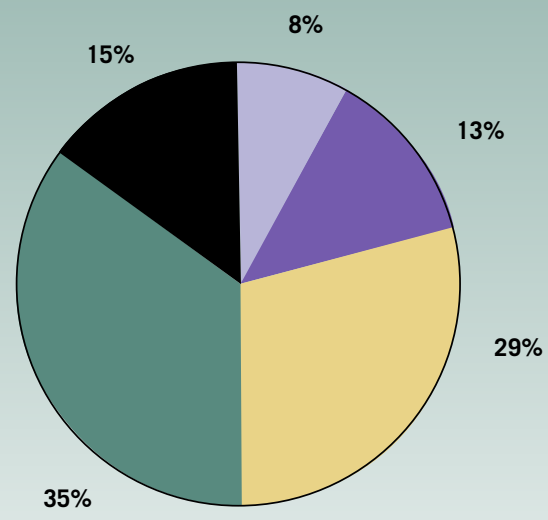

\begin{tabular}{|l|}
\hline $\begin{array}{l}\text { Fund government } \\
\text { regardless of } \\
\text { corruption }\end{array}$ \\
$\begin{array}{l}\text { Only fund local } \\
\text { government }\end{array}$ \\
$\begin{array}{l}\text { Fund outside } \\
\text { government (NGOs) }\end{array}$ \\
$\begin{array}{l}\text { No funding to } \\
\text { country until } \\
\text { government } \\
\text { fights corruption }\end{array}$ \\
World Bank \\
no impact \\
\hline
\end{tabular}

Source: Global Poll 2008, commissioned by the World Bank and carried out by Gallup

USA. Question: When there is very high corruption in acountry, and no concrete

improvement is taking place, what should an international aid agency

like the World Bank do when making decisions on funding to a developing country?

(\% respondents) WB Client sample.
- ing domestic policy reform efforts of recipient countries, even though narrow political objectives of donors still play a dominant role in many aid decisions today.

The official donor aid community has also become committed to improve aid effectiveness through better coordination mechanisms, as illustrated by the important Aid Effectiveness High Level Forum (HLF) process initiated in Rome in 2003, followed by the (unusually) substantive and concrete Paris Declaration in the Second HLF in early 2005 . At that time official donors agreed to meet certain targets by 2011, and a serious monitoring mechanism was put in place.

Even though the HLF agenda has tended to focus narrowly on donor harmonization and coordination, some governance issues have featured explicitly in the Paris agenda, which included some commitments, notably on public finance management and country procurement systems (the "supply side"). The problem of corruption was also raised, and commitments were made on transparency and "mutual accountability."

The Third HLF in Accra, in September 2008, was much more inclusive than the previous ones, significantly broadening CSO participation and giving them voice. During the Accra HLF itself, CSOs were critical of the lack of transparency on how official donor monies were being spent. They emphasized that the issue was being papered over, and demanded that such items be explicitly included in the final resolution (the "Accra Agenda for Action"). Ultimately, not only the donor aid transparency item was inserted, but also civil society engagement in tracking and monitoring projects, reduction of policy conditionality, and the elimination of tied aid.

While not path-breaking, these last minute changes signaled an "official" recognition of the role that CSOs can play. More generally, some actual progress in untying aid, conditionality, and capacity development is already apparent in practice in some places. 


\section{The Bad: the silent crisis in governance and anticorruption}

WHILE ACTUAL IMPLEMENTATION of the Paris Declaration has proceeded on some fronts, in many areas the pace of progress has been extremely slow, such as on "mutual accountability." There is high variation across donors and partners in their commitment to this agenda. Further, partner countries often see conditionality as being reshaped rather than reduced, and their own coordination on capacity development is wanting. Moreover, since the Accra HLF was held, there is scanty evidence of further concrete progress.

A commitment to transparency is certainly important for aid effectiveness, but it will not suffice on its own. Governance and anticorruption are as important, yet they were accorded little attention at the Accra HLF. The Paris Declaration was in fact further ahead on these issues than the Accra HLF communiqué. Possibly due to political sensitivities, a focus on transparency may be more palatable than addressing broader governance and corruption challenges, and talk of "transparency" may have helped secure some reluctant official signatories on board (which would be more difficult if explicit commitments were sought on media freedoms or addressing state capture and high level corruption).

More generally, the recent neglect in addressing difficult challenges in good governance and anticorruption reflects the silent crisis plaguing the governance and anticorruption movement. Contrary to the importance these issues had worldwide almost a decade ago, they have currently become a very low priority in the aid effectiveness agenda. The Accra HLF merely mirrors this development.

Fifteen years ago, governance, anticorruption and transparency in aid were largely ignored, while since the mid-1990s, multilateral and bilateral official donor agencies have paid attention to these issues. A multitude of projects and programs to assist on governance are being implemented throughout the world. Yet over the past few years, the priority accorded to governance in aid has slackened. The strategies and programs that donors implement tend to ignore those tougher governance and corruption problems that matter most for development.

In its silent crisis, the anticorruption movement has not been able to effectively make the transition from the awareness-raising stage to the concrete action-oriented stage, and from a supply-side, narrow public sector management focus to one encompassing all demand-side issues and stakeholders. The political dimensions of governance and corruption (including capture), which are key to improve aid effectiveness, have often been ignored.
Instead, the debate remains focused on supply-side discussion on "capacity;" on how donors can help "fix" technocratic issues through "harmonization" and infusion of technical assistance, by decreeing "ownership" by recipient (often governments), and by supporting yet another new institutional setup in a recipient country (e.g. project implementation units, anticorruption commissions).

At the time of the Accra HLF it should already have been abundantly clear that aid effectiveness was not to improve materially by mere efforts to "harmonize," and by further pledges to pursue "ownership," or by discussing division of labor among donors in providing "capacity building." In reality, aid effectiveness will be determined by more fundamental issues than those, such as governance.

For years already, and certainly by the time of the 2008 Accra HLF, the evidence was available that not only economic policies matter for aid effectiveness, but at least as important are good governance and corruption control. Empirical analysis indicates that governance, capture and corruption significantly affect the likelihood of a success in an aid project. More fundamentally, good governance and anticorruption are essential to ensure that aid supports domestically-led governance reforms and that it results in country-wide development and poverty alleviation. 
"FULL CIRCLE": NEW WORLD REALITY SUGGESTS LOOKING AT THE WORLD DIFFERENTLY. THE HOBO-DYER WORLD MAP PROJECTION MAY ACTUALLY MAKE SENSE NOW...

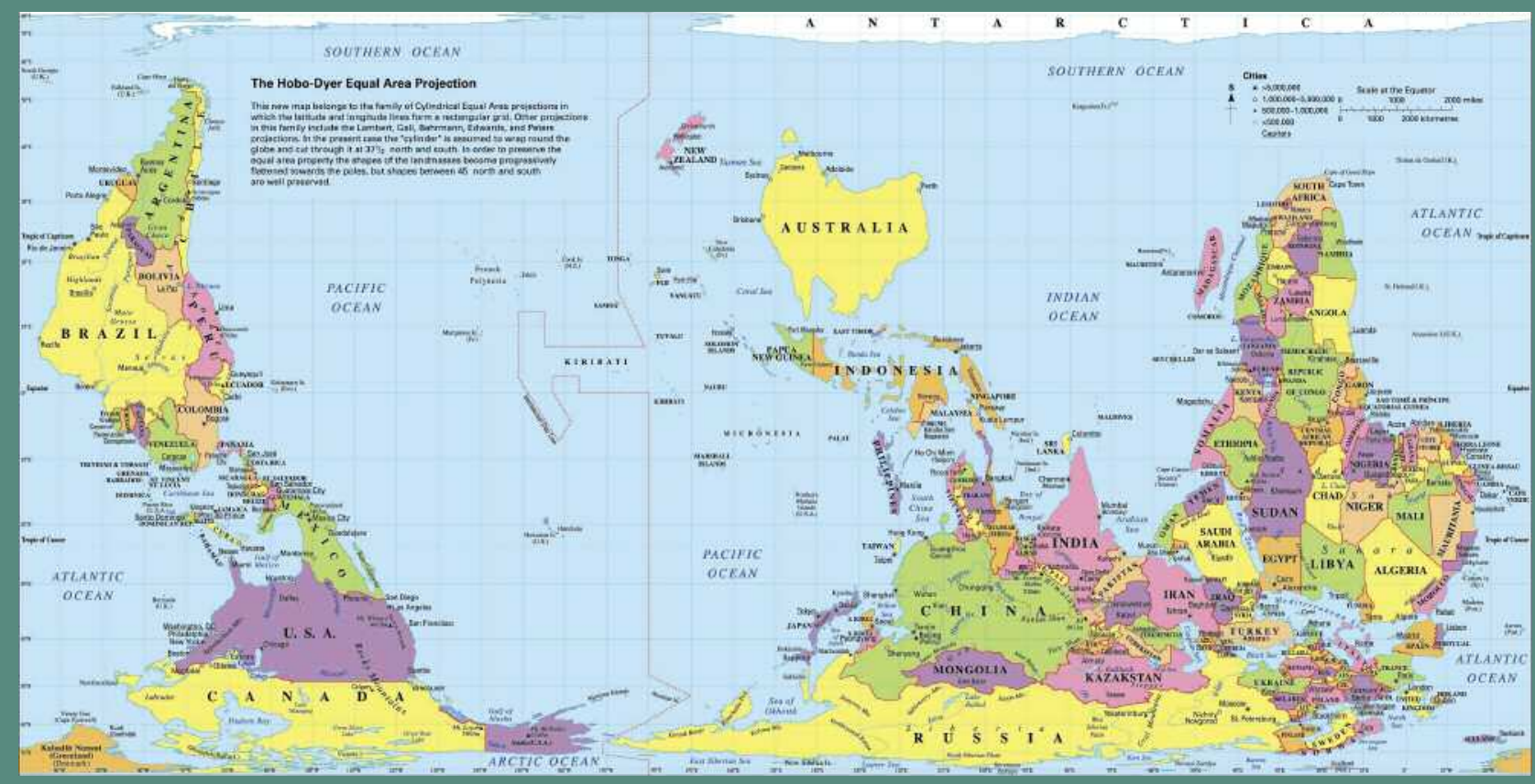

Source: @ 2004, www.ODTmaps.com. For maps and other related materials contact: ODT, Inc. at www.ODTmaps.com, or e-mail: odtstore@odt.org

\section{The Ugly: facing up to the new world reality}

THE LOW PRIORITY and tepid current approach to the governance and corruption challenge is not the only indicator that part of the "aid effectiveness" field appears to be behind the curve. Absent from Accra's HLF were the path-breaking IT innovations, in spite of the fact that they offer great promise to improve governance and aid effectiveness. Similarly, the traditional aid industry may not yet have grasped the seismic shift that has taken place as a result of private donor aid, trade, sovereign funds and new official donors such as China. Also absent from the Accra HLF were the innovative market- and private-driven solutions to development challenges.

Now facing the magnitude and implications of the global financial crisis, the fact that the aid industry is in need of a revamp has become even more clear than it was in 2008. The previous points made for reforming aid and taking governance and anticorruption seriously would not only stand nowadays, but would need to be accorded even greater importance. In light of the implications of the crisis, the particular priorities within governance may need to be altered in order to move forward.

This is because the world reality has fundamentally changed. About one-half of the financial industry in many rich countries has been wiped out, exposing major governance and corruption deficiencies in the U.S. and other powerful countries, and threatening the global

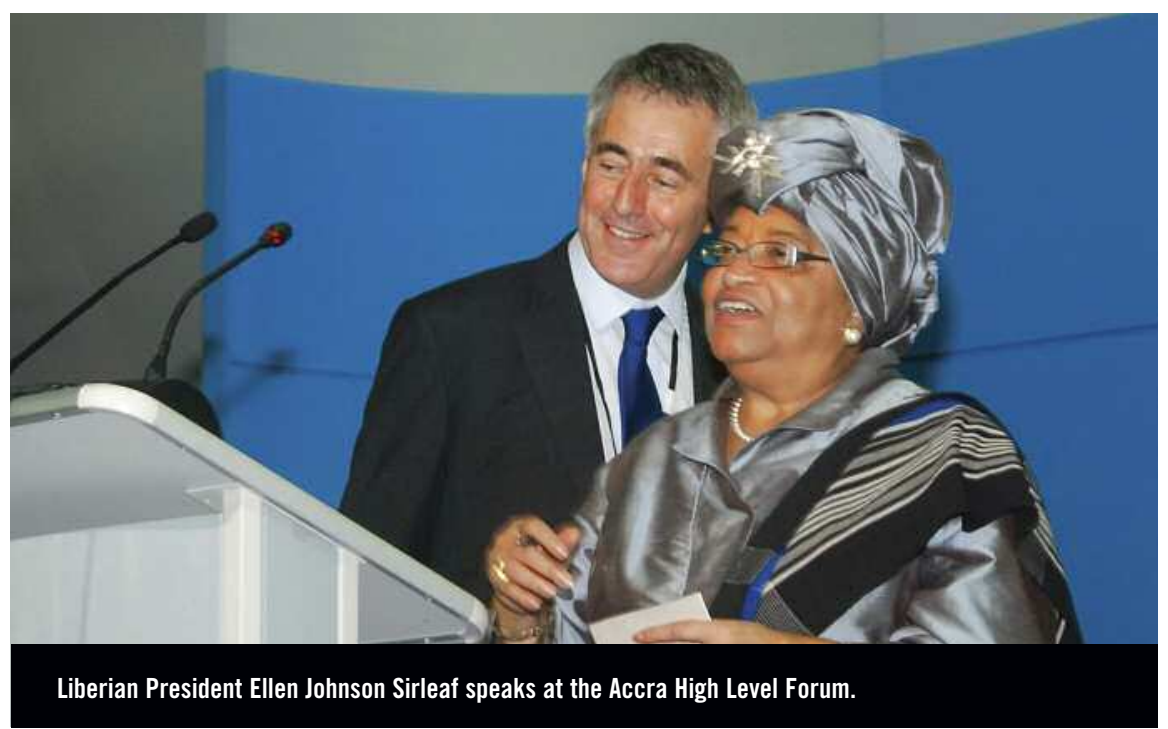

economy, which is mired in a recession. Donor aid flows to developing countries are being compromised. The U.S. is attempting to quickly disburse trillions of dollars in financial bailouts and stimulus packages, with key OECD and middle income countries following suitincluding China. Many transition and developing countries are preparing stimulus packages and, in some cases, financial bailouts as well. 
With this, the role of government is dramatically changing: government will provide major infrastructure investments, select financial institutions to provide public funds, own major financial (and other) assets; patch up social (and housing) safety nets, and also revamp and expand its regulatory role over the financial sector. Each one of these carries governance and corruption risks, which will need to be addressed, over and above the long-standing governance challenges which were pending from before.

\section{Selected implications}

SOME GIRCUMSPECTION and humility among traditional donors is in order. The governance failures leading to the financial crisis were a rude reminder that these challenges are not the exclusive domain of developing countries. Issues of capture, legal corruption and vested interests unduly influencing the rules of the game will need to be addressed in many countries, high- and low-income. Also, there is now a case for the rich world to benefit from some positive lessons already learned in developing countries. For instance, while much is made of the possible lessons from Sweden, there are also important insights that can be derived from the financial crisis of Chile in 1982. Chile also offers important lessons on methods to carry out infrastructure investments with more probity and public-private partnerships.

At the same time, given the current world economic situation, it will also be important that the donor community honor funding pledges and ensure better management of aid delivery, including untying aid and selecting types of funding and programs that maximize development effectiveness (and not necessarily always focused on central government). In addition, reformist leaders and civil society in recipient countries must show the resolve to implement governance reforms, which is paramount for development impact. In fact, developing country stakeholders (including government officials) are sending donors a message of aid selectivity and effectiveness, one which is yet to be heeded. These stakeholders are of the view that their own quality of governance should be a determinant of whether a donor like the World Bank provides funds to the country or not, and if yes, to which institution (as seen in Figure 1, from a recent poll commissioned by the World Bank).

The reforms that Liberia's President Ellen Johnson Sirleaf has been spearheading provide a good example, deserving significant support. During the Accra HLF, she called on donors to honor their funding pledges and go about it more efficiently. She has had the courage to address the challenge of corruption faced by a recipient country, and provides an illustration of the feasibility and importance of leadership from the top on this important issue. At the same time, a bottom-up approach would consist in listening to stakeholders. In another survey, we asked thousands of citizens in developing countries what they considered top priority for aid effectiveness. They invariably said that they supported improved governance and anti-corruption ahead of other options, including providing funding to their central governments.

The new world reality forces us to think again, and signals the end of the "business as usual" era. The official aid industry was already behind the curve prior to the crisis. Now the catching up that is required is vaster, necessitating a rethinking of aid strategies and the approach to aid effectiveness. There is a need for concrete attention to governance and political corruption, to the IT revolution, free media, innovations in public-private partnerships (e.g. advance market commitments in health, transparent concessions in infrastructure, provision of governance and anticorruption guarantees, EITI, etc.). It is also paramount to take in the reality of the new role in aid of non-traditional official donors as well as that of private donors. And with the new post-crisis role for governments, many of them will require specialized initiatives on governance, transparency and integrity.

Daniel Kaufmann is Senior Fellow at the Brookings Institution, and previously served as Director of Governance at the World Bank Institute. His blog is at www.thekaufmannpost.net.

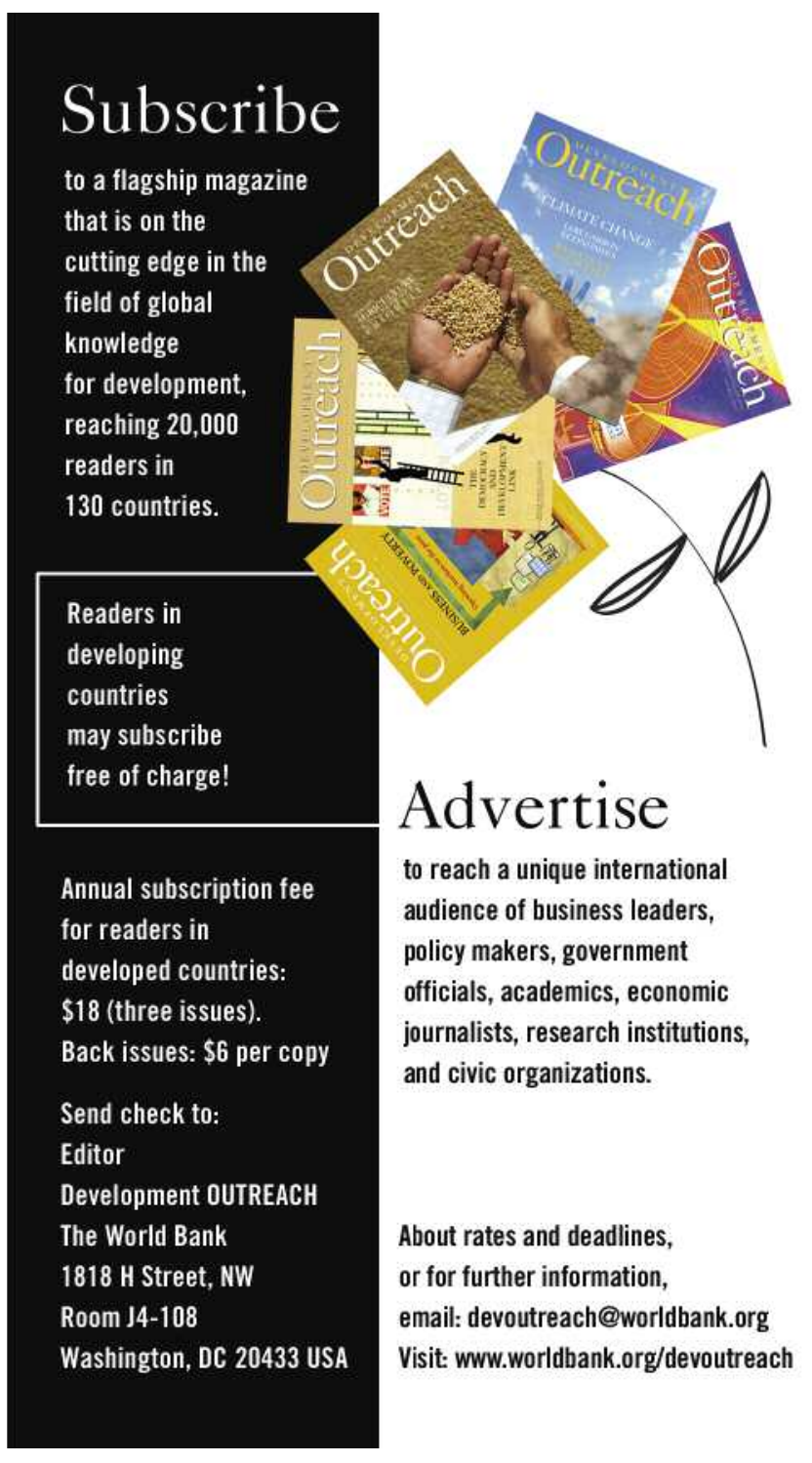

